\title{
Reducing Microvascular Dysfunction in Revascularized Patients with ST-Elevation Myocardial Infarction by Off-Target Properties of Ticagrelor versus Prasugrel. Rationale and Design of the REDUCE-MVI Study
}

\author{
Gladys N. Janssens ${ }^{1}$ • Maarten A. H. van Leeuwen ${ }^{1}$ - Nina W. van der Hoeven ${ }^{1}$. \\ Guus A. de Waard ${ }^{1} \cdot$ Robin Nijveldt $^{1} \cdot$ Roberto Diletti $^{2} \cdot$ Felix Zijlstra ${ }^{2}$. \\ Clemens von Birgelen ${ }^{3}$ - Javier Escaned ${ }^{4}$ - Marco Valgimigli ${ }^{5} \cdot$ Niels van Royen $^{1}$ \\ Received: 1 March 2016/Accepted: 5 April 2016/Published online: 21 April 2016 \\ (C) The Author(s) 2016. This article is published with open access at Springerlink.com
}

\begin{abstract}
Microvascular injury is present in a large proportion of patients with ST-elevation myocardial infarction (STEMI) despite successful revascularization. Ticagrelor potentially mitigates this process by exerting additional adenosine-mediated effects. This study aims to determine whether ticagrelor is associated with a better microvascular function compared to prasugrel as maintenance therapy after STEMI. A total of 110 patients presenting with STEMI and additional intermediate stenosis in another coronary artery will be studied after successful percutaneous coronary intervention (PCI) of the infarct-related artery. Patients will be randomized to treatment with ticagrelor or prasugrel for 1 year. FFR-guided PCI of the non-infarct-related artery will be performed at 1 month. Microvascular function will be assessed by measurement of the index of
\end{abstract}

Associate Editor Emanuele Barbato oversaw the review of this article

Gladys N. Janssens

gl.janssens@vumc.nl

1 Department of Cardiology, Institute of Cardiovascular Research ICaR-VU, VU University Medical Center, De Boelelaan 1117, 1081 HV Amsterdam, The Netherlands

2 Department of Cardiology, Erasmus Medical Center, Rotterdam, The Netherlands

3 Department of Cardiology, Medisch Spectrum Twente, Thoraxcentrum Twente and Health Technology and Services Research, MIRA Institute, University of Twente Enschede, Enschede, The Netherlands

4 Cardiovascular Institute, Hospital Clínico San Carlos, Madrid, Spain

5 Department of Cardiology, Swiss Cardiovascular Center Bern, Bern, Switzerland microcirculatory resistance (IMR) in the infarct-related artery and non-infarct-related artery, immediately after primary PCI and after 1 month. The REDUCE-MVI study will establish whether ticagrelor as a maintenance therapy may improve microvascular function in patients after revascularized STEMI.

Keywords Ticagrelor · Prasugrel · Microvascular injury · ST-elevation myocardial infarction $\cdot$ Adenosine
Abbreviations
AE Adverse event
CMR Cardiovascular magnetic resonance
DES Drug-eluting stent
FFR Fractional flow reserve
IMR Index of microcirculatory resistance
MRI Magnetic resonance imaging
MVI Microvascular injury
OCT Optical coherence tomography
PCI Percutaneous coronary intervention
RCA Right coronary artery
RHI Reactive hyperemia index
SAE Serious adverse event
STEMI ST-elevation myocardial infarction

\section{Introduction}

Percutaneous coronary intervention (PCI) in patients with STelevation myocardial infarction (STEMI) leads to an improved patency rate of the infarct-related artery, a lower incidence of heart failure, and ultimately an improved survival as compared to thrombolytic treatment [1]. However, problems 
that frequently occur after restoration of the epicardial blood flow are inadequate myocardial reperfusion and microvascular injury (MVI) [2].

MVI can be visualized by non-invasive methods using cardiovascular magnetic resonance imaging (CMR) or measured by invasive methods such as intracoronary thermodilution [3]. MVI as assessed by CMR is related to left ventricular remodeling and clinical outcome after STEMI $[4,5]$.

From the acute to late phase of a revascularized myocardial infarction, several mediators are thought to contribute to the development of MVI. These factors involve the appearance of intraluminal platelets, fibrin thrombi, and neutrophilic granulocytes, resulting in inflammatory cell plugging, formation of microthrombi, endothelial activation and injury, and finally MVI. Vasoconstriction follows as a result of endothelial dysfunction with decreased levels of nitric oxide and increased levels of endothelin-1. Furthermore, the imbalance in coagulation factors and influx of inflammatory cells can cause vascular leakage and hemorrhage $[6,7]$. Adenosine, a substance naturally present in the blood, has an inhibitory effect on several of these processes $[8,9]$.

Currently, in patients with STEMI, the $\mathrm{P}_{2} \mathrm{Y}_{12}$-receptor antagonists ticagrelor and prasugrel, in addition to aspirin, are the recommended antiplatelet drugs according to European and American guidelines [10, 11]. The efficacy of ticagrelor and prasugrel in reducing platelet activity is comparable [12]. The long-term effects on clinical outcome are presently subject to investigation [13]. Interestingly, ticagrelor, besides its antiplatelet effects, increases adenosine concentration in the blood plasma by inhibition of intracellular reuptake and might therefore have an additional beneficial effect by preventing MVI [14-17]. Therefore, we designed a randomized study, comparing the effects of ticagrelor and prasugrel on MVI and endothelial dysfunction after STEMI.

\section{Methods}

The Reducing Micro Vascular dysfunction In revascularized ST-elevation myocardial infarction patients by off-target properties of ticagrelor (REDUCE-MVI) study is a multicenter trial with a prospective, randomized, open-label, blindedendpoint (PROBE) study design. Current participating centers are the VU University Medical Center (Amsterdam, the Netherlands), the Erasmus Medical Center (Rotterdam, the Netherlands), the Medisch Spectrum Twente (Enschede, the Netherlands), and the Hospital Clínico San Carlos (Madrid, Spain). A flow chart of the study design is shown in Fig. 1.

\section{Patient Enrolment}

On hospital arrival, patients presenting with an acute STEMI will be screened for participation in the study according to the inclusion and exclusion criteria (Table 1). ST-elevation criteria are used according to current ESC guidelines [10]. After successful PCI, witnessed oral informed consent will be obtained and documented, before proceeding with study measurements. After the procedure, written informed consent in native language will be obtained from all individual participants that will be included in the study. Hereafter, patients will be randomized to treatment with either ticagrelor or prasugrel. A total of 110 patients will be enrolled in the study.

\section{Coronary Angiography and Revascularization at Index and 1 Month}

PCI will be performed according to standard procedures and is left to the discretion of the operator. All patients will receive a loading dose of heparin, aspirin, and the $\mathrm{P}^{2} \mathrm{Y}_{12}$ inhibitor ticagrelor in the ambulance before primary PCI with a third-generation drug-eluting stent (DES) (standard of care in participating centers). After successful primary PCI, myocardial tissue perfusion of the infarct-related area will be assessed by determining the myocardial blush grade [18].

After 1 month, patients will undergo clinically indicated FFR-guided PCI of the intermediate lesion in the noninfarct-related artery.

\section{Pharmacologic Treatment}

Patients will be randomly assigned to use either ticagrelor $90 \mathrm{mg}$ BID or prasugrel $10 \mathrm{mg}$ SID as a maintenance therapy continued for 1 year according to current international guidelines [19]. Concomitant medical therapy will be left to the discretion of the treating physician.

\section{Endpoints}

The primary objective of this study is to determine whether ticagrelor at treatment steady-state in revascularized STEMI patients is associated with an improved microvascular function as measured with IMR, compared to prasugrel. Both treatment groups are subjected to the same measurements at three time points. The function of the coronary microcirculation is considered as primary endpoint which will be assessed by determining the index 
Fig. 1 Flow chart of the REDUCE-MVI study. $C M R$ cardiovascular magnetic resonance, IMR index of microcirculatory resistance, $O C T$ optical coherence tomography, PCI percutaneous coronary intervention, $R H I$ reactive hyperemia index, STEMI STelevation myocardial infarction

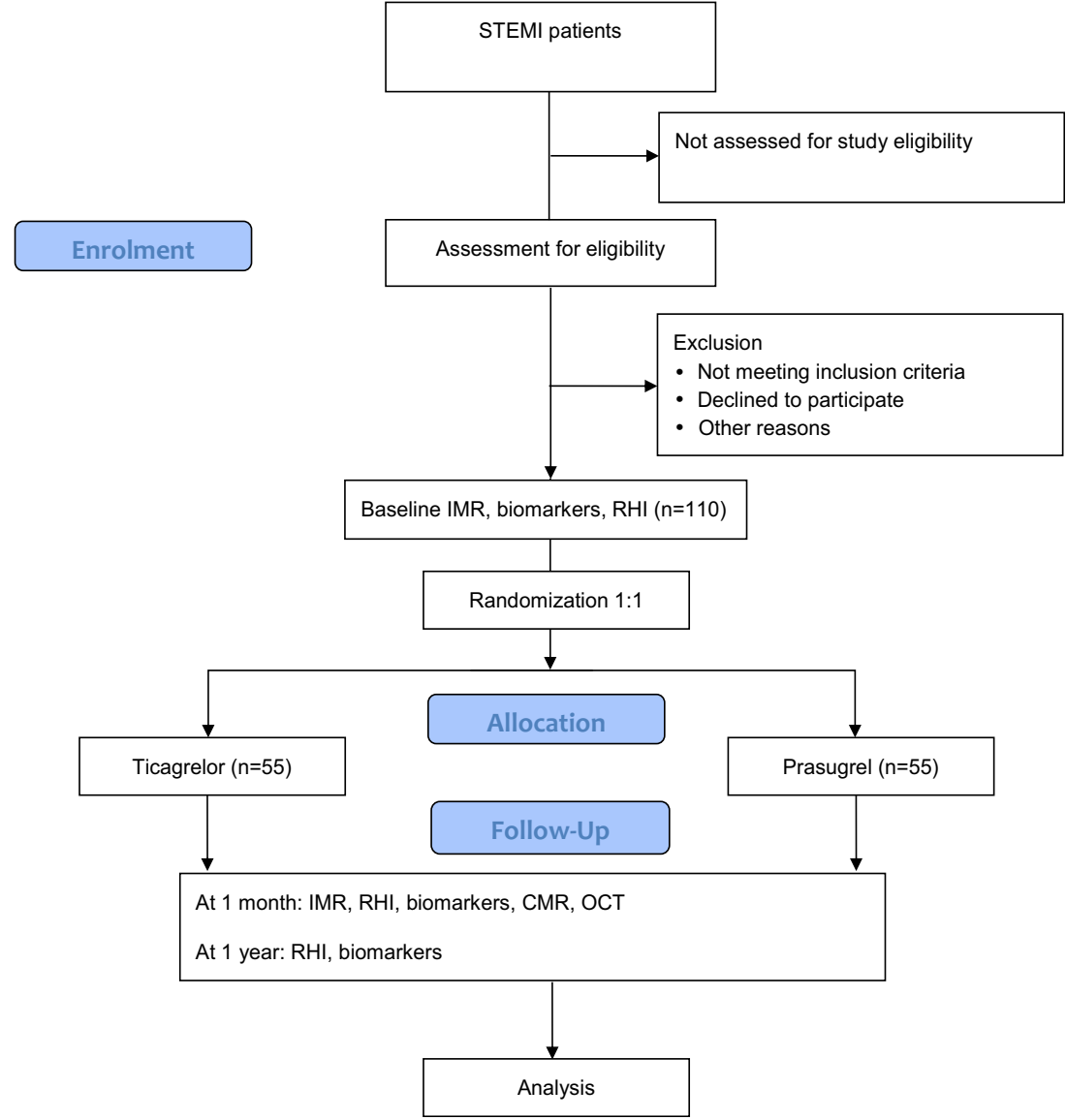

of the microcirculatory resistance (IMR) [3]. Microcirculatory resistance measurements of the infarct-related artery and secondarily of the non-infarct-related artery will be performed directly after primary PCI and after 1 month. Secondary endpoints will be coronary endothelialization, left ventricular function, and infarct size at 1 month, as well as peripheral endothelial function and several biochemical markers of endothelial function, measured at baseline and at follow-up after 1 month and 1 year.

\section{Index of Microcirculatory Resistance}

IMR in the infarct-related artery will be measured after 1 month and compared to IMR immediately after primary PCI. Secondly, IMR in the non-infarct-related artery will be determined after 1 month and compared to measurements at baseline (Fig. 2).

By using a coronary pressure and temperature-sensitive guidewire (Certus ${ }^{\text {TM}}$, ST Jude Medical, Uppsala, Sweden)

Table 1 Inclusion and exclusion criteria

\begin{tabular}{|c|c|}
\hline Inclusion criteria & Exclusion criteria \\
\hline $\begin{array}{l}\text { Acute STEMI }<12 \mathrm{~h} \\
\text { The patient has received a loading dose ticagrelor } 180 \mathrm{mg} \text { before start of PCI } \\
\text { Successful PCI of the infarct-related artery with a modern DES } \\
\text { Intermediate stenosis in a non-infarct-related artery }(50-90 \%) \\
\text { Provision of informed consent }\end{array}$ & $\begin{array}{l}\text { Age }<18 \text { or } \geq 75 \\
\text { Body weight }<60 \mathrm{~kg} \\
\text { History of myocardial infarction, coronary artery bypass graft, } \\
\quad \text { stroke, or transient ischemic attack } \\
\text { Congestive heart failure, left ventricle ejection fraction }<35 \% \\
\text { Severe liver or kidney dysfunction } \\
\text { Bleeding diathesis, platelet count }<100,000 / \mathrm{mm}^{3} \\
\text { Indication or use of (novel) oral anticoagulant therapy } \\
\text { Cardiogenic shock } \\
\text { Chronic total occlusion, left main disease } \\
\text { Inability or contra-indication for MRI } \\
\text { Inability to be followed on-site } \\
\text { Limited life expectancy }\end{array}$ \\
\hline
\end{tabular}

DES drug-eluting stent, $M R I$ magnetic resonance imaging, $P C I$ percutaneous coronary intervention, STEMI ST-elevation myocardial infarction 
and modified software, the transit time of room-temperature saline injected in a coronary artery can be determined. After an intracoronary injection of $200 \mathrm{mcg}$ nitroglycerine to establish epicardial coronary vasodilatation, the guidewire is calibrated
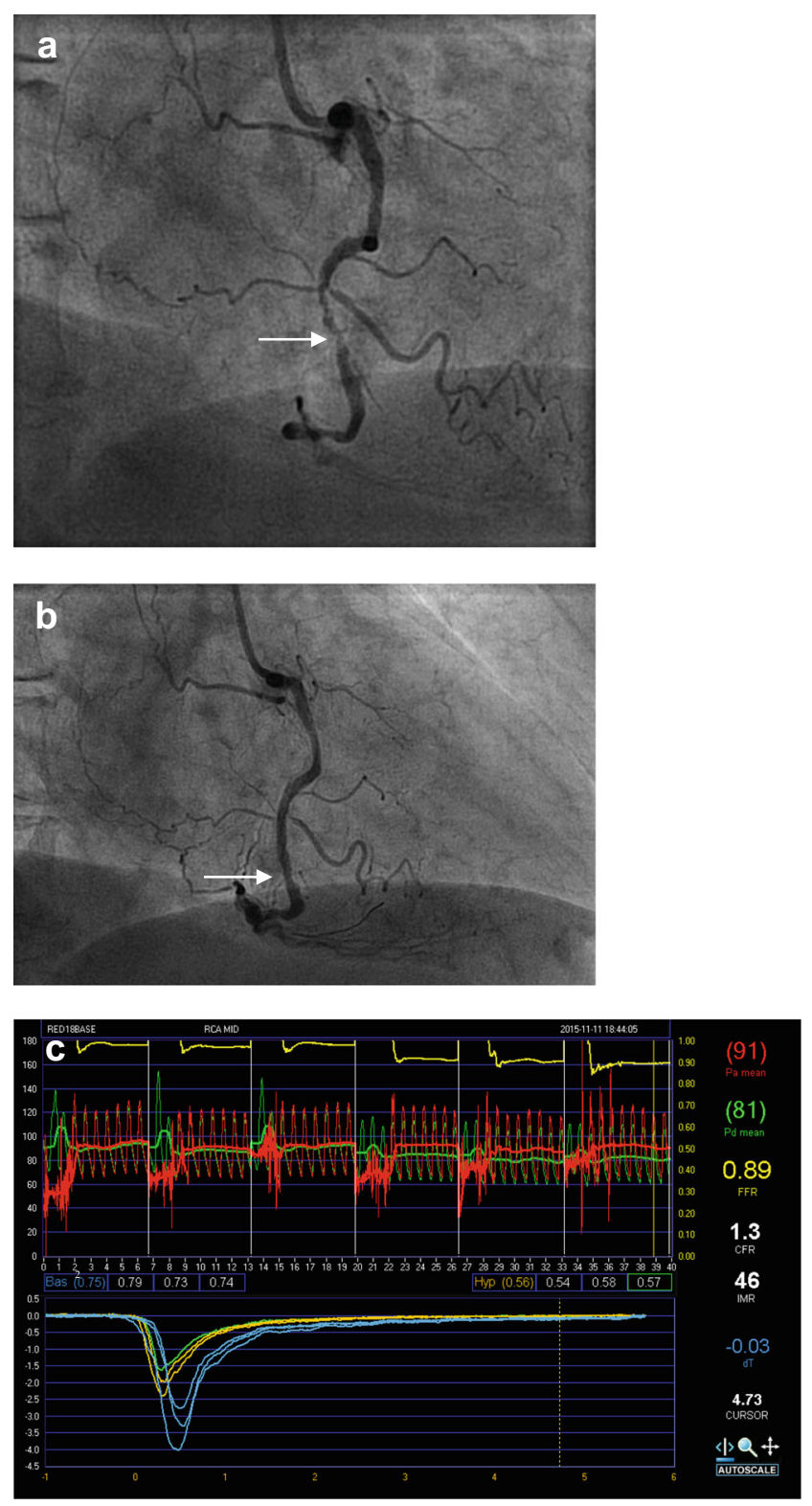

Fig. 2 Primary PCI procedure with subsequentmeasurement of the IMR. a Angiographic demonstration of the presence of a subtotal occlusion of the right coronary artery (RCA) in its mid portion and $\mathbf{b}$ final result after successful reopening of the RCA with subsequent implantation of two DES stents; $\mathbf{c}$ measurement of the IMR. The recording is obtained from a pressure wire in the mid of the right coronary artery of a patient after primary PCI. The panel is divided into two windows; the upper window displays the pressure segments recorded during each saline injection, separated from each other by white vertical lines (mean proximal arterial pressure $\left(\mathrm{P}_{\mathrm{a}}\right)=91$ and mean distal arterial pressure $\left(\mathrm{P}_{\mathrm{d}}\right)=81$ result into a fractional flow reserve $(\mathrm{FFR})=0.89)$. The lower graph displays saline injections at baseline (blue) and during hyperemia (yellow). Between the two graphs are mean transit time values at baseline (preceded by "Bas"), and during hyperemia (preceded by "Hyp") outside the body, equalized with aortic pressure at the ostium of the guide catheter, and then advanced into the distal third of the artery and distal to the stent in the infarct-related artery. The mean transit time at baseline is obtained by administering three times $3 \mathrm{~mL}$ of intracoronary saline. Thereafter, hyperemia is induced by administering adenosine at $140 \mathrm{mcg} / \mathrm{kg}$ per minute intravenously and measurement of mean transit time is repeated. Aortic and distal coronary pressures are recorded simultaneously. The distal coronary pressure divided by the inverse of the hyperemic mean transit time then provides the IMR. This calculation will be performed by independent and blinded analysts in a core laboratory.

\section{Optical Coherence Tomography}

Optical coherence tomography (OCT) will be performed at 1 month with a Dragonfly ${ }^{\mathrm{TM}}$ OCT catheter (St Jude Medical, St. Paul, MN, USA) using a motorized pullback device. OCT pullbacks will be performed at a speed of $20 \mathrm{~mm} / \mathrm{s}$ in the infarct-related and non-infarct-related arteries, using in general a contrast flush rate of $3 \mathrm{~mL} / \mathrm{s}$ in the right coronary artery and $4 \mathrm{~mL} / \mathrm{s}$ in the left coronary artery. The occurrence of subclinical stent thrombus, stent malposition, and edge dissections will be assessed. All acquired images are sent to a core laboratory for blinded evaluation (endothelial aspects of the infarct- and non-infarct-related artery) using a standardized protocol.

\section{Peripheral Endothelial Function}

The peripheral endothelial function will be measured within $24 \mathrm{~h}$ after primary PCI, at 1 month, and 1 year follow-up.

EndoPAT $^{\circledR}$ (Itamar Medical Ltd., Caesarea, Israel) is a validated device indicated for non-invasive endothelial and microvascular function assessment [20-22]. EndoPAT ${ }^{\circledR}$ will be used to measure the finger arterial pulsatile volume changes that indicate changes in vascular tone, by modified plethysmographic probes placed on the index finger of each hand [23]. The measurements will be performed at rest in a convenient, low stimulus environment. Each recording consists of subsequently $5 \mathrm{~min}$ of baseline measurement, $5 \mathrm{~min}$ of occlusion time of the brachial artery by a blood pressure cuff, and 5 min post-occlusion measurement (hyperemic period). Measurements will be performed on the contralateral arm of the access site of angiography. The access site extremity is used as a reference to control for concurrent nonendothelial-dependent systemic changes in vascular tone.

The reactive hyperemia index (RHI) and its natural logarithm are then calculated as the ratio of the magnitude of the average post-occlusive pulse volume amplitude to the average 
pre-occlusive pulse volume amplitude, corrected for baseline vascular tone.

\section{Cardiovascular Magnetic Resonance}

After 1 month and optionally at baseline (day 2-7), CMR will be performed with a 1.5 or 3.0 Tesla scanner using a phased array cardiac receiver coil. All images are ECG-gated and acquired during mild end-expiration breath-holding. Cine longand short-axis slices are obtained to examine regional and global left ventricular function, volumes, and ejection fraction. Evaluation of myocardial ischemia will be assessed with firstpass perfusion imaging of a gadolinium-based contrast agent during the administration of $140 \mathrm{mcg} / \mathrm{kg}$ per minute of adenosine intravenously. Finally, late gadolinium-enhanced (LGE) images are acquired $10 \mathrm{~min}$ after perfusion imaging, to identify the size and extent of myocardial infarction and, in addition, the presence and extent of MVI. When performed at baseline, T2weighted imaging will be acquired in short-axis planes for the detection of intramyocardial hemorrhage and infarct-related edema. All CMR analyses will be performed in a core laboratory by blinded observers using a standardized protocol.

\section{Blood Collection and Storage}

Blood samples for laboratory testing will be drawn at baseline and at 1 month and 1 year follow-up according to standard procedures. The testing includes standard biochemistry and hematology tests (e.g., renal function tests, cardiac biomarkers, lipid profile, and blood cell counts). Furthermore, extra blood samples will be collected and stored at $-80{ }^{\circ} \mathrm{C}$. At the end of the study, all samples will be analyzed by the laboratory at the VU University Medical Center. The plasma levels of ticagrelor will be examined as well, and $\mathrm{P}_{2} \mathrm{Y}_{12}$ inhibition levels will be assessed by VerifyNow testing (Accumetrics, San Diego, CA, USA). The effect of ticagrelor on inflammatory markers and cells, such as cell adhesion molecules and monocytes, will be studied concomitantly. In addition, the level of biochemical markers for endothelial function, like asymmetrical dimethylarginine, will be measured, which allows linking these results to the microvascular function.

\section{Registration of Adverse Events}

Adverse events (AEs) are evaluated and registered during index hospitalization and at 1 month and 1 year follow-up. AEs occurring in external participating centers will be reported to the sponsor. A serious adverse event (SAE) is a severe undesirable event in which there was no necessarily causality with the study. The relationship of SAEs to study treatment or procedures will be assessed by the investigators and communicated to AstraZeneca.

As a safety measure, bleeding complications will be monitored during the entire study period, categorized to the most recent criteria (Bleeding Academic Research Consortium, Thrombolysis in Myocardial Infarction [24], and Global Use of Strategies to Open Occluded Coronary Arteries [25]) and analyzed for both treatment groups.

Once a year, the sponsor will submit a safety report to the accredited medical ethics committee and competent authority. After $50 \%$ inclusion, an interim analysis will be performed, with respect to safety endpoints, AEs, and SAEs. An independent data safety monitoring board, composed of experienced cardiologists and a statistician, will be responsible for reviewing patient safety and study integrity.

\section{Sample Size Calculation}

The study is powered using a superiority design with the null hypothesis that IMR will be significantly improved in the ticagrelor group in comparison to the prasugrel group. A difference of IMR means of 7 at 1 month follow-up between the two treatment groups, with a standard deviation of 12 , is expected [26]. To be able to reject the null hypothesis that the means of both treatment groups are equal with a power of $80 \%$ (with significance level $\alpha=0.05$ ), 47 subjects in each group are required. Assuming a loss of follow-up of maximally $15 \%$, it will be necessary to include a total of 110 patients in the study. After $50 \%$ inclusion $(n=55)$ with complete 30-day follow-up, an interim analysis will be performed to verify the assumed standard deviation and, if necessary, we might adjust the total sample size needed to achieve an adequate power.

\section{Discussion}

Optimal therapy of STEMI requires both treatment of the macrovasculature and the microvasculature. Over the years, treatment of the macrovasculature has improved notably. Due to refined stent designs and more biocompatible polymers on DESs, the prevalence of acute stent thrombosis and restenosis has been reduced significantly. However, inadequate myocardial perfusion after restoration of the epicardial blood flow by primary PCI is present in a large proportion of STEMI patients. Nearly $50 \%$ of the final myocardial infarct size is due to myocardial reperfusion injury, and thus, a logical target for reducing myocardial infarct size, thereby maximizing the benefits of reperfusion [27].

The cornerstone of treatment of patients after STEMI is antithrombotic therapy with a $\mathrm{P}_{2} \mathrm{Y}_{12}$-receptor antagonist and aspirin. According to current ESC and ACCF/AHA guidelines, both ticagrelor and prasugrel have a class 1B 
recommendation for use after STEMI $[10,11]$. Both of these drugs have advantages over clopidogrel as they achieve a more rapid, consistent, and stronger platelet inhibition than clopidogrel with improved outcomes [28, 29]. With regard to the efficacy in inhibiting platelet function, ticagrelor and prasugrel have comparable effects [12]. Currently, the ISARREACT 5 study is enrolling patients to compare ticagrelor and prasugrel for clinical outcome [13].

It has been shown that ticagrelor, besides its antiplatelet effects, also has the potency of increasing the plasma concentration of endogenous adenosine in patients with acute coronary syndromes. Adenosine is produced particularly after tissue damage by hypoxia, and ticagrelor has the ability to inhibit intracellular uptake through the adenosine equilibrative nucleoside transporter 1 (ENT1). Prasugrel and clopidogrel, two other $\mathrm{P}_{2} \mathrm{Y}_{12}$-receptor antagonists, do not mediate such conservation of the plasma adenosine concentration $[15,16]$. This indicates that ticagrelor might be a superior drug for treating STEMI.

There is evidence that elevations of adenosine reduce the inflammatory response in the different phases after revascularized myocardial infarction, by interfering with the production of inflammatory mediators and oxygen species and neutrophil trafficking $[8,9]$.

In the acute phase of myocardial infarction, myocardial damage is enhanced by the formation of microthrombi as a result of a hypercoagulable state and by inflammatory cell clogging of the intramyocardial microvasculature. In the early phase (hours to days), infiltrating cells further amplify damage, as an influx of blood-borne inflammatory cells leads to production of inflammatory mediators and tissue-destructive agents such as metalloproteinases [30]. In the late phase of myocardial infarction (days to months), which is characterized by irreversible damage of the microcirculation, adenosine might also have beneficial effects, as it stimulates at elevated levels angiogenesis by the induction of endothelial progenitor cell migration [31]. Only effective angiogenesis and arteriogenesis will be able to restore microvascular and macrovascular tissue perfusion to prevent increased scarring. Furthermore, adenosine may have a stimulatory effect on endothelial healing, which may be particularly favorable in patients who underwent successful primary PCI for STEMI.

In these ways, adenosine might reduce ischemia and reperfusion injury, preserving microvascular function. This might be most important for patients with STEMI, as coronary MVI and dysfunction appear to be most pronounced in this patient group, compared to patients with non-ST-elevation acute coronary syndrome [32].

In the REDUCE-MVI study, we aim to investigate the potential adenosine-mediated effects of ticagrelor with several outcome parameters, especially IMR, to determine the effect on coronary microvascular function.
In the coming years, more insight into the biochemical mechanisms involved in STEMI may be expected, which may hopefully lead to the development of more specific drugs for microvascular preservation. Along this line, the REDUCEMVI study is focused in more detail on current therapeutic options to retain microvascular integrity and function in patients with STEMI.

Compliance with Ethical Standards All procedures that will be performed in this study involving human participants are in accordance with the ethical standards of the institutional and national research committee and with the 1964 Helsinki Declaration and its later amendments or comparable ethical standards.

Funding The study is financially supported by AstraZeneca.

Human and Animal Rights and Informed Consent No animal studies will be carried out by the authors for this article.

ClinicalTrials.gov Identifier Number NCT02422888

Open Access This article is distributed under the terms of the Creative Commons Attribution 4.0 International License (http:// creativecommons.org/licenses/by/4.0/), which permits unrestricted use, distribution, and reproduction in any medium, provided you give appropriate credit to the original author(s) and the source, provide a link to the Creative Commons license, and indicate if changes were made.

\section{References}

1. Zijlstra, F., Hoorntje, J. C., de Boer, M. J., Reiffers, S., Miedema, K., Ottervanger, J. P., van 't Hof, A. W., \& Suryapranata, H. (1999). Long-term benefit of primary angioplasty as compared with thrombolytic therapy for acute myocardial infarction. New England Journal of Medicine, 341, 1413-9.

2. Teunissen, P. F., de Waard, G. A., Hollander, M. R., Robbers, L. F., Danad, I., Biesbroek, P. S., Amier, R. P., Echavarria-Pinto, M., Quiros, A., Broyd, C., Heymans, M. W., Nijveldt, R., Lammertsma, A. A., Raijmakers, P. G., Allaart, C. P., Lemkes, J. S., Appelman, Y. E., Marques, K. M., Bronzwaer, J. G., Horrevoets, A. J., Van Rossum, A. C., Escaned, J., Beek, A. M., Knaapen, P., \& van Roven, N. (2015). Doppler-derived intracoronary physiology indices predict the occurrence of microvascular injury and microvascular perfusion deficits after angiographically successful primary percutaneous coronary intervention. Circulation. Cardiovascular Interventions, 8, e001786.

3. Ng, M. K., Yeung, A. C., \& Fearon, W. F. (2006). Invasive assessment of the coronary microcirculation: superior reproducibility and less hemodynamic dependence of index of microcirculatory resistance compared with coronary flow reserve. Circulation, 113, 2054-61.

4. Wu, K. C., Zerhouni, E. A., Judd, R. M., Lugo-Olivieri, C. H., Barouch, L. A., Schulman, S. P., Blumenthal, R. S., \& Lima, J. A. (1998). Prognostic significance of microvascular obstruction by magnetic resonance imaging in patients with acute myocardial infarction. Circulation, 97, 765-72.

5. Nijveldt, R., Beek, A. M., Hirsch, A., Stoel, M. G., Hofman, M. B., Umans, V. A., Algra, P. R., Twisk, J. W., \& Van Rossum, A. C. (2008). Functional recovery after acute myocardial infarction: 
comparison between angiography, electrocardiography, and cardiovascular magnetic resonance measures of microvascular injury. Journal of the American College of Cardiology, 52, 181-9.

6. Reffelmann, T., \& Kloner, R. A. (2004). Microvascular alterations after temporary coronary artery occlusion: the no-reflow phenomenon. Journal of Cardiovascular Pharmacology and Therapeutics, 9, 163-72.

7. Jaffe, R., Charron, T., Puley, G., Dick, A., \& Strauss, B. H. (2008). Microvascular obstruction and the no-reflow phenomenon after percutaneous coronary intervention. Circulation, 117, 3152-6.

8. Barletta, K. E., Ley, K., \& Mehrad, B. (2012). Regulation of neutrophil function by adenosine. Arteriosclerosis, Thrombosis, and Vascular Biology, 32, 856-64.

9. Csoka, B., Nemeth, Z. H., Rosenberger, P., Eltzschig, H. K., Spolarics, Z., Pacher, P., Selmeczy, Z., Koscso, B., Himer, L., Vizi, E. S., Blackburn, M. R., Deitch, E. A., \& Hasko, G. (2010). A2B adenosine receptors protect against sepsis-induced mortality by dampening excessive inflammation. Journal of Immunology, $185,542-50$.

10. Steg, P. G., James, S. K., \& Gersh, B. J. (2013). 2012 ESC STEMI guidelines and reperfusion therapy: evidence-based recommendations, ensuring optimal patient management. Heart, 99, 1156-7.

11. O'Gara, P. T., Kushner, F. G., Ascheim, D. D., Casey, D. E., Jr., Chung, M. K., de Lemos, J. A., Ettinger, S. M., Fang, J. C., Fesmire, F. M., Franklin, B. A., Granger, C. B., Krumholz, H. M., Linderbaum, J. A., Morrow, D. A., Newby, L. K., Ornato, J. P., Ou, N., Radford, M. J., Tamis-Holland, J. E., Tommaso, C. L., Tracy, C. M., Woo, Y. J., Zhao, D. X., Anderson, J. L., Jacobs, A. K., et al. (2013). 2013 ACCF/AHA guideline for the management of ST-elevation myocardial infarction: a report of the American College of Cardiology Foundation/American Heart Association Task Force on Practice Guidelines. Journal of the American College of Cardiology, 61, e78-140.

12. Alexopoulos, D., Xanthopoulou, I., Gkizas, V., Kassimis, G., Theodoropoulos, K. C., Makris, G., Koutsogiannis, N., Damelou, A., Tsigkas, G., Davlouros, P., \& Hahalis, G. (2012). Randomized assessment of ticagrelor versus prasugrel antiplatelet effects in patients with ST-segment-elevation myocardial infarction. Circulation. Cardiovascular Interventions, 5, 797-804.

13. Schulz, S., Angiolillo, D. J., Antoniucci, D., Bernlochner, I., Hamm, C., Jaitner, J., Laugwitz, K. L., Mayer, K., von Merzljak, B., Morath, T., Neumann, F. J., Richardt, G., Ruf, J., Schomig, G., Schuhlen, H., Schunkert, H., \& Kastrati, A. (2014). Randomized comparison of ticagrelor versus prasugrel in patients with acute coronary syndrome and planned invasive strategy-design and rationale of the iNtracoronary stenting and antithrombotic regimen: rapid early action for coronary treatment (ISAR-REACT) 5 trial. Journal of Cardiovascular Translational Research, 7, 91-100.

14. van Giezen, J. J., Sidaway, J., Glaves, P., Kirk, I., \& Bjorkman, J. A. (2012). Ticagrelor inhibits adenosine uptake in vitro and enhances adenosine-mediated hyperemia responses in a canine model. Journal of Cardiovascular Pharmacology and Therapeutics, 17, 164-72.

15. Armstrong, D., Summers, C., Ewart, L., Nylander, S., Sidaway, J. E., \& van Giezen, J. J. (2014). Characterization of the adenosine pharmacology of ticagrelor reveals therapeutically relevant inhibition of equilibrative nucleoside transporter 1. Journal of Cardiovascular Pharmacology and Therapeutics, 19, 209-19.

16. Bonello, L., Laine, M., Kipson, N., Mancini, J., Helal, O., Fromonot, J., Gariboldi, V., Condo, J., Thuny, F., Frere, C., Camoin-Jau, L., Paganelli, F., Dignat-George, F., \& Guieu, R. (2014). Ticagrelor increases adenosine plasma concentration in patients with an acute coronary syndrome. Journal of the American College of Cardiology, 63, 872-7.
17. Cattaneo, M., Schulz, R., \& Nylander, S. (2014). Adenosinemediated effects of ticagrelor: evidence and potential clinical relevance. Journal of the American College of Cardiology, 63, 2503-9.

18. Van't Hof, A. W., Liem, A., Suryapranata, H., Hoorntje, J. C., de Boer, M. J., \& Zijlstra, F. (1998). Angiographic assessment of myocardial reperfusion in patients treated with primary angioplasty for acute myocardial infarction: myocardial blush grade. Zwolle myocardial infarction study group. Circulation, 97, 2302-6.

19. Windecker, S., Kolh, P., Alfonso, F., Collet, J. P., Cremer, J., Falk, V., Filippatos, G., Hamm, C., Head, S. J., Juni, P., Kappetein, A. P., Kastrati, A., Knuuti, J., Landmesser, U., Laufer, G., Neumann, F. J., Richter, D. J., Schauerte, P., Sousa, U. M., Stefanini, G. G., Taggart, D. P., Torracca, L., Valgimigli, M., Wijns, W., \& Witkowski, A. (2014). 2014 ESC/EACTS Guidelines on myocardial revascularization: The Task Force on Myocardial Revascularization of the European Society of Cardiology (ESC) and the European Association for Cardio-Thoracic Surgery (EACTS) developed with the special contribution of the European Association of Percutaneous Cardiovascular Interventions (EAPCI). European Heart Journal, 35, 2541-619.

20. Hamburg, N. M., \& Benjamin, E. J. (2009). Assessment of endothelial function using digital pulse amplitude tonometry. Trends in Cardiovascular Medicine, 19, 6-11.

21. Kandhai-Ragunath, J. J., Jorstad, H. T., de Man, F. H., Peters, R. J., \& von Birgelen, C. (2013). Approaches for non-invasive assessment of endothelial function: focus on peripheral arterial tonometry. Netherlands Heart Journal, 21, 214-8.

22. Kandhai-Ragunath, J. J., Jorstad, H. T., de Wagenaar, B., de Man, F. H., Stoel, M. G., van Es, J., Doelman, C. J., Doggen, C. J., Peters, R. J., \& von Birgelen, C. (2014). Assessment of the relation between initial culprit vessel patency in acute ST-elevation myocardial infarction and endothelial function. EuroIntervention, 10, 784-91.

23. Suessenbacher, A., Dorler, J., Wanitschek, M., Alber, F., Pachinger, O., \& Frick, M. (2014). Prognostic value of peripheral arterial tonometry in patients with coronary artery disease and a high cardiovascular risk profile. Journal of Atherosclerosis and Thrombosis, 21, 230-8.

24. Kikkert, W. J., van Geloven, N., van der Laan, M. H., Vis, M. M., Baan, J., Jr., Koch, K. T., Peters, R. J., de Winter, R. J., Piek, J. J., Tijssen, J. G., \& Henriques, J. P. (2014). The prognostic value of bleeding academic research consortium (BARC)-defined bleeding complications in ST-segment elevation myocardial infarction: a comparison with the TIMI (Thrombolysis in Myocardial Infarction), GUSTO (Global Utilization of Streptokinase and Tissue Plasminogen Activator for Occluded Coronary Arteries), and ISTH (International Society on Thrombosis and Haemostasis) bleeding classifications. Journal of the American College of Cardiology, 63, 1866-75.

25. The GUSTO investigators. (1993). An international randomized trial comparing four thrombolytic strategies for acute myocardial infarction. New England Journal of Medicine, 329, 673-82.

26. Hirohata, A., Yamamoto, K., Hirose, E., Kobayashi, Y., Takafuji, H., Sano, F., Matsumoto, K., Ohara, M., Yoshioka, R., Takinami, H., \& Ohe, T. (2014). Nicorandil prevents microvascular dysfunction resulting from PCI in patients with stable angina pectoris: a randomised study. EuroIntervention, 9, 1050-6.

27. Frohlich, G. M., Meier, P., White, S. K., Yellon, D. M., \& Hausenloy, D. J. (2013). Myocardial reperfusion injury: looking beyond primary PCI. European Heart Journal, 34, 1714-22.

28. Wallentin, L., Becker, R. C., Budaj, A., Cannon, C. P., Emanuelsson, H., Held, C., Horrow, J., Husted, S., James, S., Katus, H., Mahaffey, K. W., Scirica, B. M., Skene, A., Steg, P. G., Storey, R. F., Harrington, R. A., Freij, A., \& Thorsen, M. (2009). Ticagrelor versus clopidogrel in patients with acute coronary syndromes. New England Journal of Medicine, 361, 1045-57. 
29. Wiviott, S. D., Braunwald, E., McCabe, C. H., Montalescot, G., Ruzyllo, W., Gottlieb, S., Neumann, F. J., Ardissino, D., De, S. S., Murphy, S. A., Riesmeyer, J., Weerakkody, G., Gibson, C. M., \& Antman, E. M. (2007). Prasugrel versus clopidogrel in patients with acute coronary syndromes. New England Journal of Medicine, 357, 2001-15.

30. Ziegler-Heitbrock, L., Ancuta, P., Crowe, S., Dalod, M., Grau, V., Hart, D. N., Leenen, P. J., Liu, Y. J., MacPherson, G., Randolph, G. J., Scherberich, J., Schmitz, J., Shortman, K., Sozzani, S., Strobl, H., Zembala, M., Austyn, J. M., \& Lutz, M. B. (2010). Nomenclature of monocytes and dendritic cells in blood. Blood, 116, e74-e80.
31. Fernandez, P., Jara, C., Aguilera, V., Caviedes, L., Diaz, F., Radojkovic, C., Veas, C., Lamperti, L., Escudero, C., \& Aguayo, C. (2012). Adenosine A(2)A and A(3) receptors are involved in the human endothelial progenitor cells migration. Journal of Cardiovascular Pharmacology, 59, 397-404.

32. Layland, J., Carrick, D., McEntegart, M., Ahmed, N., Payne, A., McClure, J., Sood, A., McGeoch, R., MacIsaac, A., Whitbourn, R., Wilson, A., Oldroyd, K., \& Berry, C. (2013). Vasodilatory capacity of the coronary microcirculation is preserved in selected patients with non-ST-segment-elevation myocardial infarction. Circulation. Cardiovascular Interventions, 6 , 231-6. 